\title{
ACERCA DA NOVITAS JOACHIMITA COMO REVERSÃO DA TRADICIONAL CONCEPÇÃO CRISTÃ DA HISTÓRIA
}

Oscar Federico Bauchwitz ${ }^{\star}$

SINTESE - O pensamento da história de Joaquim de Fiore representa uma alternativa à tradicional concepção cristã, pautada no exemplarismo agostiniano. A Era do Espírito expressa um princípio próprio do movimento de realização da história, no qual o presente é pela disposição de seu passado e em função de seu futuro.
ABSTRACT - The history's meaning of Joachim of Fiore represents an alternative to the traditional Christian conception, based on the agostinian exemplarism. The Age of Spirit expresses the movement of history realization, in which the present is for disposition of its past and in function of its future.

Certamente é pelo seu pensamento da história que Joaquim de Fiore é condenado à sombra da heresia. Como vimos, a sua teologia não apresenta uma disposição em contestar a tradicional fé e os dogmas cristãos, ou ao menos não de uma forma tal que pudesse levá-lo a seguidas condenações. ${ }^{1}$ Residem, portanto, na sua compreensão da história os elementos que motivaram a Igreja a posicionar-se severamente contra as obras do abade calabrês. Talvez o mais significativo na perspectiva eclesiástica seja o fato de Joaquim ter a sua obra popularizada e de ser tomada como guia por alguns movimentos reformadores da época. A dissolução da Igreja, por exemplo, que na interpretação joaquimita possui um sentido determinado, seria para tais movimentos a indicação de que a Igreja Romana estaria perto de seu fim, atrelada como estava às questões temporais da luta pelo poder e que deveria ser substituída por uma nova estrutura, por novos princípios, com certeza, mais éticos e próximos do exemplo dado em vida por Jesus. Contudo, não procuramos resguardar a teologia de Joaquim condenando a sua compreensão da história e nem o inverso. Sabemos que ambas se articulam e desfazer-se de uma é deixar a outra em petição de princípio. Se agiu bem a Igreja ao condenar a obra Joaquimita, visando com isso arrefecer os ânimos reformadores que se agitavam em seu pró-

* Universidade Federal do Rio Grande do Norte - UFRN - Natal.

1 A primeira condenação é feita pelo Concilio de Latrão IV, em 1215; a segunda através do chamado "Protocolo de Agnani" em 1255, motivada pelo Introductorius de Gerardo de San Donino; a terceira pelo Sinodo de Arles, em 1263. 
prio seio, se de fato alcançou êxito (o que parece pouco provável), ou então, se houve realmente uma leitura isenta das obras de Joaquim, são questões que permanecerão sem respostas. A questão que nos propomos é compreender a história a partir de Joaquim, procurando por aquilo que faz dele um dos mais fecundos pensadores da filosofia medieval.

Desde a sua origem, o problema da história esteve presente, no pensamento cristão, ${ }^{2}$ ocupando lugar de destaque nas obras da Patrística. Sendo uma religião que supostamente supera o judaísmo, o cristianismo soube colher nesse o que poderia ser-lhe útil na elaboração de seus dogmas e na própria estruturação de poder da Igreja. A crença num único Deus, a queda do primeiro homem ("e por este a morte passou a todos os homens"), ${ }^{3}$ as diversas provações por que passaram tanto os judeus quanto os cristãos primitivos, a espera do messias (para os cristãos confirmada por Cristo), são alguns dos pontos que estabelecem profundo contato entre as duas religiões. Contudo, é a criação do mundo e seu fim, atestado pelos discursos proféticos do Antigo Testamento e pela Revelação do Novo, que impõem o problema da história. Segundo o Gênesis, "No princípio Deus criou"; ${ }^{4}$ este ato criador traz em si uma clara distinção entre a eternidade divina, que cria o mundo com o tempo, e o tempo que possibilita a história. O tempo pertence tão somente à criatura e, por isso mesmo,vale dizer, tempo e história se co-pertencem. Isto significa que ao homem, enquanto criatura "caida", resta-lhe apenas fazer-se homem ao fazer a história. Este é o seu lugar e é nela que deve traçar o caminho de volta à origem, a eternidade do Criador.

A afirmação da criação do mundo não deixou de parecer estranha aos povos que viram surgir o cristianismo. É verdade que os judeus já a afirmavam, mas somente com os cristãos a idéia de um mundo criado por um único Deus atravessou as fronteiras da Palestina. ${ }^{5} \mathrm{O}$ povo de Israel, como bem se sabe, é zeloso de suas tradições e sempre manteve o seu Deus para ele próprio, ao contrário do que ocorre pela difusão evangelista. Por isto e pelo legado cultural tomado dos antigos, vale lembrar a célebre expressão de Justino - "Tudo que já se disse de acertado, por quem que seja, pertence a nós cristãos" ${ }^{\prime \prime}$ - o cristianismo

2 A idéia de um pensamento ou de uma "filosofia cristā", apresentada por Gilson (in Histónia da Filosofia Cristā) não deixa de ser paradoxal. Contra esta idéia posicionou-se Heidegger, entendendo que uma filosofia cristã è como um "ferro de madeira", tal a incompreensão destes dois termos (Introdução à Metafísica, p. 38). A expressão aqui é utilizada para demarcar uma certa época e não para designar uma determinada filosofia.

3 Conforme Epistola aos Romanos 5,12.

4 O texto hebraico diz: "Bereschit bara Elohim". A tradução deste versículo não deixaria de trazer diversas convicções, entre estas é de notar-se a do cristianismo que viu na pluralidade do termo Elohim a confirmação da Trindade. Deve-se ainda considerar que entre os nomes que recebe a Divindade no Antigo Testamento, Joaquim utilizaria em diversas figuras o de IEUE, que se deriva do tetragrama YHVH. De toda forma é a idéia de um princípio que é colocado.

5 Segundo a interpretação de A. Donini: "Os evangelhos foram pensados e redigidos longe da Palestina, em ambientes ainda ligados ao judaísmo, mas já sob a influência de motivos religiosos orientais e helenísticos, de inspiraçāo não bíblica". In Histónia do Cristianismo, p. 39.

6 Apologia II, 13. Conforme Boehner e Gilson in História da Filosofia Cristã, p. 31. 
travou acirradas contendas na defesa da hipótese criacionista e de todos os seus dogmas, dos quais o mais espantoso para um espírito clássico seria o da morte de Deus crueificado. ${ }^{7}$ Entretanto, se por um lado o cristianismo, historicamente, sagrou-se o vencedor de tais rusgas, e neste caso a vitória significa a própria mantença da fé - haja vista a crise que ocasiona o averroísmo latino ao defender a eternidade do mundo - por outro lado não impediu ou não logrou impedir outras perspectivas, pelas quais o ato criador não é visto de forma que se exclua da história o principio que a engendra, fazendo daquela uma instância desprovida de algum sentido que não o da transitoriedade salvacionista mas, isto sim, perspectivas que fazem retornar à história a eternidade do princípio e entendem que a salvação se encontra na própria história. Estas variantes não significam uma contestação do versículo genesíaco. Mesmo Tomás de Aquino, principal opositor de Siger de Brabant, ancora-se na fé para aceitar como verdade a criação do mundo, pois à razão não é permitido demonstrar ou certificar tal ato. Trata-se, então, de uma profissão de fé, deve-se aceitá-la e com esta aceitação mover o pensamento na busca de um sentido para o homem e a história. Mas, se é a fé que garante a existência de um começo, é ela mesma que supõe um fim.

É certo que na tradicional concepção cristã, o fim da história não é algo que possa ser previsto ou esperado para um determinado momento. Desde Agostinho, as expectativas de um fim próximo, que povoaram o imaginário dos primeiros tempos do cristianismo, foram consideradas "fábulas ridículas de quiliastás". ${ }^{8}$ A idéia de um eschatós, no sentido agostiniano, remete para um além ${ }^{9}$ as esperanças de uma vida verdadeira. No entanto, estas esperanças não são apenas frutos de perseguições ou das dificuldades que enfrentaram os primeiros cristãos, elas encontram fundamento no Novo Testamento e principalmente no Apocalipse. Mais que uma idéia fabulosa, a perspectiva apocalíptica é, antes de tudo, uma interpretação, uma hermenêutica das imagens descritas pelo último dos livros bíblicos e das promessas de Jesus, expressas pelo Consolador ou Paráclito. Esta interpretação, embora sofresse a condenação do Bispo de Hipona, responsável por uma das mais influentes compreensões da história, permaneceu viva durante toda a Idade Média e se manifestou através de diversos movimentos milenaristas que acreditavam, diante da degradação dos principios puramente cristãos, estar à beira do fim.

Em termos agostinianos, o que acontece entre a criação e a consumação dos tempos é sempre a história da salvação. É um objetivo bem claro o que se impõe à

7 Em um de seus romances mais conhecidos A morte dos deuses - $O$ romance de Juliano, apóstata, Merejovski apresenta um suposto diálogo entre Libânio de Antióquia e João Crisóstomo. Este último e o Imperador Juliano teriam sido alunos de Libânio. No diálogo Libânio teria dito ao cristão: "A verdade é que por milhares de anos olhamos para o que vive. Agora, vocês olham para o que está morto, adoram um homem morto e dizem que este mundo não é para nós, e que o outro mundo é que importa. Só que não existe o outro". É importante lembrar que Merejovski é autor do sugestivo 0 Terceiro Testamento de Cristo.

8 A Cidade de Deus 20, VII.

9 O termo grego éschatos tanto designa o fim como também um mais além. Na escatologia judaicocristã, o primeiro sentido é próprio dos profetas; o segundo é propriamente cristão. 
história ao contrário da clássica visão dos antigos de um eterno retorno, pelo qual não há princípio nem fim e o tempo acompanha a revolução cíclica dos corpos celestes, a compreensão cristã da história parte em busca das implicações morais do ato criador, daí a distinção entre os herdeiros de Caim e Abel ${ }^{10}$ que acaba por dividir a história e os homens numa dicotomia moralizadora. Desta perspectiva moralizante a história recebe um sentido definido que promete a felicidade. Assim, a visão cristã da história serve de base às modernas teorias do progresso, ${ }^{11}$ dotando a história de um sentido que, na verdade, não se origina dos acontecimentos ou da própria vida mas apenas de uma certa moral e da perspectiva de realização de algo imaginado ou suposto pela fé. A promessa de salvação, expressa pela Antiga e Nova Alianças, faz da história um intervalo entre o seu inicio e seu fim. Sem o pecado original e a redenção final, a história se tornaria desnecessária e ininteligível. Viver tal intervalo é viver na expectativa do cumprimento da promessa; o que já se deu, segundo a tradicional interpretação cristã, no aparecimento histórico de Jesus. O mistério da encarnação e ressurreição é o ápice e o centro da história. É o ápice na medida em que nenhum outro evento pode superá-lo em grandeza e é o centro pois a partir dele o sentido da história, anterior e posterior, se desvenda.

A idéia de que em Cristo se encontra o centro da história é fundamental ao cristianismo. Sobre isto é esclarecedora a análise de Cullmann sobre a história da salvação. De fato, o que narram as Escrituras é um duplo movimento histórico: "O primeiro vai de muitos para o Único. É esta a Velha Aliança. O outro vai do Único para os muitos. É esta a Nova Aliança. Precisamente no meio encontra-se o factum decisivo, a morte de Cristo" ${ }^{12}$ Estando no meio da história, o Cristo é o mediador entre Deus e os homens. ${ }^{13} \mathrm{E}$, por ser o único caminho para a salvação, não haveria por que se esperar por outro acontecimento que cumprisse a Aliança. Cristo é aquele que leva a cabo os designios de Deus e quem fornece à história um verdadeiro sentido.

Ao se compreender que a história possui uma divisão fundamental, até e a partir de Cristo, compreende-se que as objeções feitas por Agostinho às esperanças escatológicas residem no fato de que a história tenha já alcançado a sua plenitude. Não haveria por que aguardar em vida por um acontecimento tão importante. A idéia de que é na cristologia que repousa o centro da história permitiu ao próprio Agostinho uma outra divisão histórica mais detalhada e que tem como base a exemplar semana da criação. À semelhança de Deus que, em seis dias fez todas as coisas e no sétimo descansou, o homem, porque também obra, conhece seis épo-

10 A Cidade de Deus 15, II.

11 Sobre o sentido do progresso na perspectiva cristă da histónia ver K. Lowith, O Sentido da Histónia (especialmente o cap. IX).

12 Cf. citação de Lowith op. cit., p. 184.

13 A definição de Cristo como logos está expressa no Evangelho de João. No entanto, nota Heidegger, o sentido de logos no Evangelho está longe do seu sentido originário, tal como está em Heráclito. op. cit., p. 159. "Logos não significa, como em Heráclito, o ser do ente [...] mas entende significar um ente particular, o Filho de Deus". 
cas na história, propriamente temporais, e uma sétima época, não epocal pois que é eterna, na qual terá o "sábado perpétuo", o descanso eterno. Estas são as épocas da história, segundo Agostinho: "A primeira estende-se de Adão ao dilúvio, a segunda, de Noé a Abraão e a terceira de Abraão até Davi. A quarta vai de Davi até o Exílio na Babilônia; a quinta, do Exilio até o nascimento de Jesus. A sexta e última época estende-se da primeira à segunda vinda de Cristo no fim do mundo". ${ }^{14}$ Esta etapa histórica não tem um limite definido e a estaríamos vivendo até hoje. 0 fundamental para Agostinho não é a diferença de centenas ou milhares de anos que durará a era cristã mas o fato de o mundo ser criado e transitório.

$\mathrm{O}$ vigor intelectual de Agostinho fez-se presente durante todo o medievo. 0 Mestre do Ocidente, na expressão de Gilson, excerceu profunda influência, durante séculos, na filosofia medieval. Contudo, a sua concepção da história encontraria a sua superação através de Joaquim de Fiore. Em que consiste esta superação, que é propriamente o pensamento da história de Joaquim, é o que veremos a seguir.

A primeira observação a ser feita sobre o pensamento da história de Joaquim de Fiore é a que diz da superação da perspectiva agostiniana. É de fato uma superação. Contudo, esta não significa um abandono ou um esquecimento do que pensou Agostinho. Trata-se de um movimento que ultrapassa os ensinamentos do Mestre levando-os às últimas conseqüências e que apresenta novos elementos para pensar um aspecto da história que Agostinho não tratou de resolver, ou ao menos, na situação em que vivia, não era oportuno pensar. Joaquim recebe da tradição agostiniana o conceito de exemplarismo e é sobre ele que funda a sua compreensão. Mas, enquanto toda a tradição colocava em Cristo o centro da história, Joaquim, rompendo com esta tradição, coloca a própria Trindade como centro e modelo exemplar de toda a história. Não apenas o Filho se apresenta na história mas todas as pessoas da Trindade mantêm uma relação de semelhança que determina todas as criaturas. Como vimos ao expor a sua teologia, para Joaquim, todas as pessoas relacionam-se com a criatura, a qual traz em si essa semelhança. Mesmo Agostinho reconhece uma trina semelhança na criação e, principalmente, no interior da alma de cada homem, fato este que Joaquim lembra no Psalterium Decem Chordarum. ${ }^{15}$ Agora, o que Joaquim estabelece a partir de uma interpretação das Escrituras - e de uma revelação - é que a história e o homem, bem como Deus que tudo gerou, é trina e, enquanto tal, divide-se em Três Eras ou Estados, aos quais corresponde cada pessoa da Trindade. Assim, a história é a Era do Pai, a Era do Filho e a Era do Espírito Santo.

A divisão trina da história é notadamente a mais característica das elaboradas por Joaquim. Entretanto, a história pode ser dividida em quatro, cinco, sete, nove e em quinze etapas. ${ }^{16}$ Estas variações estão dispersas por toda a sua obra, mas têm como base a disposição das Três Eras ou Estados, expostas no seu primeiro livro, Concordia Novi et Veteris Testamenti, e que é suposta por Joaquim nas suas obras

14 A Cidade de Deus 22, XXX.

15 Psalt. p. 151: "Si autem secundum quod Augustinus docet, in typo memoriae, rationis et amoris, unusquisque est potentia, sapientia et amor, restat ut nihil minus sit singulus quam simul tres".

16 A divisão em quatro tempos pertence unicamente ao Tractatus super quatuor Evangelia; a divisão em cinco tempos ao Psalterium: a de sete tempos mormente ao Tractatus, embora esteja presente no Psalterium. As demais pertencem ao Liber Figuranum e à Concordia. 
posteriores. Portanto, é necessário que apresentemos esta divisão da história conforme Joaquim a descreve nessa obra. Ele diz:

"Os mistérios das divinas páginas mostram-nos, enfim, os Três Estados do mundo. O primeiro é aquele no qual estivemos sob a lei; o segundo no qual estamos sob a graça; o terceiro, que esperamos iminente, sob uma graça ampliada... Por isso o primeiro Estado foi na ciência; o segundo na posse da sabedoria; o terceiro na plenitude do sentido. $O$ primeiro na servidão servil; o segundo na servidão filial; o terceiro na liberdade. $O$ primeiro nos flagelos; 0 segundo na ação; o terceiro na contemplação. O primeiro no temor; o segundo na fé; o terceiro na caridade. O primeiro é dos servos; o segundo é dos filhos; o terceiro é dos amigos. O primeiro é dos velhos; o segundo é dos jovens; o terceiro das crianças. O primeiro na luz da estrela; o segundo na aurora; o terceiro ao meio-dia. O primeiro no inverno; o segundo na primeira; o terceiro no verão. $O$ primeiro produz urtigas; o segundo rosas; o terceiro lírios. 0 primeiro ervas; o segundo espigas, o terceiro o trigo. O primeiro a água; o segundo o vinho; o terceiro o óleo. O primeiro pertence à Setuagésima; o segundo à Quaresma; o terceiro à festa pascal. O primeiro Estado pertence ao Pai, que é criador de todas as coisas; o segundo ao Filho, que se dignou assumir nosso limite; o terceiro ao Espírito Santo do qual diz o apóstolo: 'Onde se achar o Espírito do Senhor ai está a liberdade'.".

Esta passagem encerra os principais elementos do pensamento de Joaquim. Embora muitas das características de cada Estado possuam um forte simbolismo, elas trazem, explicitamente ou não, o que há de fundamental na novidade joaquimita. A definição dos Três Estados diz respeito ao movimento de manifestação da Trindade e articula-se com os atributos de cada pessoa. Assim, a Era do Pai é o período no qual os homens vivem sob o rigor da lei, no Temor e, portanto, são como servos ou escravos. Historicamente é a época do Antigo Testamento, o tempo que vai até o aparecimento de Cristo. Na Era do Filho os homens presenciam a graça e a generosidade do Filho que se fez homem; os homens deste período vivem a Sabedoria e relacionam-se com Deus como seus filhos. É a época do Novo Testamento, que se inicia com Cristo e que teria fim no ano de 1260. A Era do Espírito, que é a novidade, é o tempo no qual os homens viverão e conhecerão uma graça ainda maior e, através da Caridade, serão como amigos de Deus. Este é o tempo, segundo a interpretação espiritual das Escrituras, que se inicia após o periodo do Fiho.

Notamos uma clara distinção entre Joaquim e a tradicional concepção da história, que é a afirmação de uma graça ampliada. Já vimos como é difícil para o cristianismo aceitar que algum outro evento histórico pudesse superar o fato único

17 Concordi Novi et Veteris Testamenti V, 84: "Tres denique mundi status divinae nobis paginae sacramenta commendat. Primo in quo fuimus sub lege; secundus in quo sumus sub gratia; tertius, quem e vicino expectamus, sub ampliori gratia... Primus ergo status in scientia fuit; secundus in potestate sapientiae; tertius in plenitudine intellectus. Primus in servitude servili; secundus in servitude filiali; tertius in libertate. Primus in flagellis; secundus in actiones; tertius in contemplatione. Primus in timore; secundus in fide; tertius in charitate. Primus status servorum este; secundus liberorum; tertius amicorum. Primus senum; secundus iuvenum; tertius pueronum. Primo in luce siderum; secundus in aurora; tertius in perfecto die. Primus in hieme; secundus in exordio veris; tertius in aestate. Primus protulit urticas; secundus rosas; tertius lilia. Primus herbas; secundus spicas; tertius triticum. Primus aquam, secundus vinum, tertius oleum. Primus pertinet ad septuagesimam; secundus ad quadragesimam; tertius ad festa paschalia. Primus itaque status pertinet ad Patrem, qui est auctor omnium; secundus ad Filium, qui assumere dignatus est limum nostrum; tertius ad Spiritum Sanctum de quo dicit Apostolus: "Ubi Spiritus Domini ibi libertas" (Cf. citação de Crocco op. cit., p. 78). 
e irrepetivel da morte e ressurreição de Cristo. Não obstante esta dificuldade, Joaquim afirma uma Era do Espírito, que expressa a superação da Era Cristã, e a supera de tal forma que aqueles que viverem na Era do Espírito, porque poderão compreender o mistério de Deus e o da história, porque estarão de posse da plenitude do sentido, prescindirão da própria fé e serão livres.

A conseqüência imediata de tal distinção é o fim da Era do Filho. Somente é possível se pensar e aguardar o início da Era do Espírito em razão de ter a Era do Filho uma duração determinada. Esta duração, no entanto, de modo algum faz de Joaquim um milenarista ou um pensador escatológico, como alguns chegam a afirmar. ${ }^{18}$ Estamos longe de aceitarmos tal idéia. Não é milenarista, pois a data que pressupõe como sendo o ínicio da Era do Espírito não marca o final dos tempos ou a parusia; não é escatológico pois não há um fim; e se aceitarmos que Joaquim reconhece um fim, deve-se dizer que é um fim que é um princípio. É certo que ele atesta uma duração tanto para a Era pré-cristã quanto para a Era Cristã, mas isenta-se de estabelecer um término para a Era do Espirito. $O$ final dos tempos em Joaquim, bem como para a própria tradição, identifica-se com o Juízo Final.

A idéia de um millennium (Apo. 20) que fomentou diversos movimentos não encontra amparo em Joaquim. No Expositio in Apocalypsim, obra que juntamente com a Concordia e o Psalterium, compõe a sua trilogia, Joaquim deixa claro que "nos mil anos designam-se todos os tempos que decorrem desde a ressurreição do Senhor até o fim do mundo". ${ }^{19}$ Mas, então, como devemos entender a frase de Crocco que diz ser Joaquim o "mais famoso hermeneuta do Apocalipse de toda Idade Média" ${ }^{20}$ É verdade que a análise que ele apresenta no Expositio obteve profunda influência e formou escola, principalmente entre os "espirituais" franciscanos, cuja ressonância maior reside no episódio do Introductorius de Gerardo. ${ }^{21} \mathrm{E}$ é justamente no Expositio que estão presentes os elementos que, sem dúvida, trouxeram decepções aos seus seguidores, como é o caso do magnus tyrannus ${ }^{22}$ e do Praedicatur veritatis, ${ }^{23}$ pontos fundamentais de sua análise sobre o Apocalipse. Muitos joaquimitas que aguardavam ardentemente pelo início da Era do Espírito, segundo Joaquim precedida por tribulações e perseguições até a chegada do líder (novus dux), viram as suas esperanças morrerem junto com o imperador Frederico II, em 1250, dez anos antes da data marcada e quando, finalmente, 1260 chegou e nada do que a profecia joaquimita afirmava, aconteceu. Contudo, estas "falhas"da interpretação joaquimita não invalidam a sua compreensão da história. A idéia do anticristo pertence ao cristianismo e é tão antiga quanto o próprio Cristo. Naquele

18 Jacques Le Goff, A Civilização do Ocidente Medieval. Vol II, p. 300 e Abbagnano, Nicola, Dicionário de Filosofia. Ambos incluem Joaquim nos verbetes sobre o Milenarismo. Curioso é que Abbagnano o coloca junto com Kant em tal verbete.

19 Expositio V, f. 211 r': "In mille annis designatur omne tempus quod decurrit a resurrectione Domini usque in finem mundi" (Cf. citação de Crocco op. cit. p. 51).

20 Crocco op. cit. p. 44.

21 Sobre o assunto ver nossa Introdução.

22 Historicamente o magnus tyrannus costuma ser identificado com o Imperador Henrique IV, da dinastia Hohenstaufen, na época de Joaquim e mais tarde, com o seu filho Frederico II.

23 A idéia de um predicador da verdade seria tomada pelos espirituais, que viram em Francisco tal atribuição. Em Joaquim esta idéia designa o início da Era do Espírito. 
foram identificados os responsáveis pelas perseguições e, em muitos casos, aqueles que hesitavam em se deixar tutelar pela Igreja. Que esteja presente numa obra joaquimita não é surpreendente e muito menos fundamental. Portanto, se aceitarmos como legítima a afirmação de Crocco, então é preciso que se diga que na sua análise do Apocalipse, não obstante as imprecisões proféticas, estão presentes as características mais importantes do pensamento de Joaquim: a divisão trina da história, as três ordens de homens e a liberdade no Espírito. $\mathrm{O}$ que se esclarece na seguinte passagem:

"O primeiro dos três Estados foi sob o tempo da lei, quando o povo do Senhor, ainda criança
e sujeito aos elementos mundanos, era incapaz de considerar a liberdade do Espírito até que
viesse aquele que diz: 'Se o filho vos libertar, sereis realmente livres' (Jo. 8,36). O. segundo
Estado foi sob o Evangelho e permanece até agora, na liberdade certamente, se comparado
ao Estado precedente, mas não na liberdade se comparado ao futuro. O terceiro Estado terá
inicio por volta do fim do século, já näo sob o véu da letra mas na plena liberdade do Espíri-
to". ${ }^{24}$

É de se notar um movimento de dupla libertação. Os homens do primeiro Estado, "sujeitos aos elementos mundanos", estão presos à lei e encontram em Jesus a primeira libertação. Mas esta não é plena. É preciso que mesmo a liberdade que o filho proporciona seja superada para que no futuro os homens evangelizados sejam realmente livres. Esta liberdade provém do Espirito. A história é, portanto, um caminho em direção à liberdade que, voltamos a lembrar, se dará na história ("por volta do fim do século") e não fora dela.

Até aqui aludimos à data que Joaquim preconiza como sendo o começo da terceira Era. É preciso agora que apresentemos qual o argumento que leva Joaquim a afirmar o ano de 1260 como tal data. Segundo o Evangelho de Mateus, as gerações que antecederam o Cristo são: "De Abraão até Davi, quatorze gerações; de Davi até o Exílio na Babilônia, quatorze gerações; e do Exílio na Babilônia até Cristo, quatorze gerações". Ao todo são quarenta e duas gerações. O número 42 multiplicado pelos 30 anos de cada geração fornecem o número 1260 . Sabe-se, entretanto, que a idade de cada geração não foi sempre de trinta anos, mas o que Joaquim procura não é propriamente a idade mas a base mística do número trinta, que se refere à Trindade e também ao fato de que Jesus tinha trinta anos quando iniciou a sua vida pública, começando a ter os seus primeiros filii spirituales. A outra explanação sobre esta data está no Expositio e parte da fuga para o deserto da "mulher vestida com o sol" onde lá permaneceu 1260 dias. Esta mulher, como diz Joaquim, "designa a Igreja Universal dos Católicos" ${ }^{25}$ Logo, a própria Igreja deve preparar-se para a sua superação, quando da Era do Espirito.

24 Expositio Lib. Introductorius V, f.5 r: "Primus trium statuum fuit sub tempore legis, quando populus Domini adhuc pro tempore parvulus serviens erat sub elementis huius mundi, non valens adipisci libertatem spiritus, quousque veniret ille qui ait: 'Si Filius vos liberaverit, vere liberi eritis'. Secundus status fuit sub Evangelio et manet usque nunc, in libertate quidem respectu praeteriti, sed non in libertate respectu futuri. Tertius ergo status erit circa finem saeculi, iam non sub velamine litterae, sed in plena spiritus libertate" (Cf. Crocco, op. cit., p. 80).

25 Ibid. IV, f. 154 v': "Igitur haec Mulier amicta sole generaliter designat universam catholicorum Ecclesiam" (Crocco, op. cit., p. 50). 
Já dissemos que ao pensar a história Joaquim parte da idéia de um exemplarismo mas que, de alguma forma, opera uma superação de tal idéia ao apresentar novos elementos que servem à consideração da história. É preciso demonstrar o que estamos a dizer.

A história até aqui apresentada possui certos marcos divisórios: A Era do Pai vigora até a chegada do Cristo; a Era do Filho permanece até o ano de 1260 e, finalmente, a Era do Espírito que tem datação para seu início mas não para seu fim. Bem, estas Eras marcam a história pontualmente, transformam o exemplarismo, radicalizando-o numa semelhança trina, mas não é somente isto a novidade que Joaquim apresenta. $O$ que realmente leva Joaquim à afirmação da Era do Espírito, além dos argumentos exegéticos que veremos adiante, é o movimento da própria história e mais que da história, é próprio da vida. Ao dizer que a história possui aetates ou status, Joaquim não deixa de ter em mente que o mundo tem uma certa idade. E é justamente esta noção de idade, de duração de vida, de permanência, de aparecimento e desaparecimento, de nascimento e morte, que fornecem a Joaquim a sua compreensão da história.

Certamente o primeiro, mas não decisivo, argumento que conduz à convicção da Era do Espírito é o teológico. Como vimos, é em razão de ter uma definição sobre as propriedades e atividades das pessoas divinas é que Joaquim pode encontrar um nexo entre a Trindade e a História, a relação ad extra. No entanto, este argumento não é decisivo pois, mantendo-se na.órbita do exemplarismo, não fornece uma explicação "orgânica" do desenvolvimento histórico, ${ }^{26}$ de como uma época possibilita a sua posterior; de que forma historicamente uma Era nasce, floresce e declina e uma outra superando este declínio, nasce em seu lugar.

A elaboração de uma explicação orgânica do desenvolvimento histórico não implica, em nosso entendimento, na busca de um princípio meta-histórico. Se, como diz Joaquim, a história é "cognoscível para ser amada e reconhecida", ${ }^{27}$ então é necessário que exista um princípio realmente histórico que se faça presente a cada momento. Este princípio, como colocamos em nossa Introdução, é um princípio derivado, um principio numa segunda acepção, que fornece à história um sentido próprio. A divindade parece perder um pouco de sua força e providência mas, se considerarmos que a história é sempre a história dos homens e que estes espelham os atributos pessoais de Deus, então veremos que Deus é reafirmado não como um princípio inerte e exterior à história mas como um princípio que vive a história e que a possibilita concedendo-lhe o movimento constante de geração e corrupção. O Deus Trino demarca três etapas da história e engendra nesta um outro princípio que a realiza enquanto história. Tal princípio, repetimos, é declínio e superação.

Do exposto acima, talvez, pudéssemos colocar o seguinte problema: Se Deus se manifesta na história, através das Três Pessoas em três épocas distintas, embora todas juntas ao mesmo tempo, poder-se-ia então perguntar se não está o mesmo Deus sujeito a este segundo princípio que, a rigor, é próprio somente das criaturas,

26 Dos comentadores da obra de Joaquim, somente H. Mottu aventa a hipótese de um princípio numa segunda acepção, tal como sustentamos aqui (op. cit., p. 219).

27 Psalt. p. 180 . Ver nota 15 de nossa Introdução. 
na medida em que dele depende para o transitar de sua graça. Como Deus pode realmente cumprir a promessa de salvação senão porque é da história tal princípio? Um tal questionamento acabaria por trazer à atividade ad extra um movimento que é inexistente nas relações $a b$ intra e mais que isso, comprometeria a eternidade divina, sujeitando-a a um princípio temporal. Ora, a dificuldade é notória pois em se aceitando tal suposição aceitar-se-ia que Deus precisa da história tanto quanto o homem que, em termos cristãos, nela encontra a possibilidade de salvação.

Este problema, no entanto, não se coloca para Joaquim. Deus näo tem necessidade da história mas, ao contrário, a história existe em função do homem. Que exista um princípio propriamente histórico e que somente na história esteja presente se deduz da própria idéia de Deus, no qual não há transmutação ou vicissitu$\mathrm{des}^{28}$ ele é "um princípio sem principio, o que não começa alguma vez a ser, mas sempre era aquilo que é" ${ }^{29}$ É princípio incondicionado e condição de todo existente. Não precisa da história senão em razão de sua bondosa disposição salvacionista, e isto não o condiciona a outro princípio senão que este é por Ele imposto às criaturas, à história. Está presente na história não por necessidade mas por sua vontade. Nessa se manifesta e em se manifestando, como num acúmulo de graça, possibilita ao homem a sua superação e então, "nesse momento ver os extraordinários mistérios". . $^{30}$

A Era do Espírito é a manifestação histórica do Espírito Santo. Não, decerto, como um acontecimento histórico semelhante ao que marcou o início da Era do Filho, mas como uma efusão maior do "espírito de verdade". Dos argumentos exegéticos que Joaquim apresenta ao longo de sua obra atemo-nos ao que é fundamental ao terceiro Estado: a vinda do Paráclito. Expresso no discurso de despedida de Jesus, o Paráclito é uma promessa e, enquanto tal, o seu cumprimento é uma questão de tempo. Claro está que este tempo é a Era do Espírito. Mas, este tempo é o quinto e o último, segundo a divisão histórica que Joaquim apresenta no Psalterium, onde ele analisa a promessa do Paráclito, afirmando uma manifestação histórica do Espírito, além daquela que ocorreu no Pentecostes, quando o Espírito desceu sobre os apóstolos. Não deixa de ser oportuno notar que o Psalterium é dedicado ao Espírito Santo e que foi durante as festividades pentecostais que Joaquim recebeu a elucidação do mistério trinitário. ${ }^{31}$

A divisão apresentada no Psalterium é talvez a mais importante do ponto de vista da relação entre a Trindade e a história. Ela é colocada logo em seguida que Joaquim disserta sobre as cinco relações ${ }^{32}$ pessoais e, portanto, esta divisão tem como fim não apenas uma demarcação histórica, mas, principalmente, uma divisão pela qual cada tempo determinado expressa uma das relações interpessoais. Assim, no primeiro tempo Abraão recebe o significado da primeira relação, Deus

28 Psalt. p. 177: "apud Deum autem non est transmutatio nec vicissitudinis obumbratio".

Ibid. p. 173, "principium sine principio, quia non aliquando coepit esse, sed semper erat quod est".

Ibid. p. 217: "Oui sic orat et psallit laudans et invocans deum suum [...] excedit hominem, supergreditur angelum, requiescit in deo. Ibi respicit mira misteria".

Ibid. p. 89: "[...] et conterritus nehementer compulses nem invocare Spiritus Sanctum, cui sacra solemitas erat", e p. 91.

Ver capitulo anterior. 
manda-lhe um filho como enviará o seu próprio Filho. No segundo tempo, o Filho alude à relação com o Pai através do Anjo do Senhor que orienta o povo de Israel na travessia do deserto introduzindo-o na terra prometida. No terceiro tempo, semelhante à terceira relação, o Espírito Santo se apresenta através dos reis e profetas, como quando Samuel unge Davi; é a imagem, ainda que velada, da Trindade. ${ }^{33}$ De forma reduzida, Joaquim assim descreve os três primeiros tempos:

"Porque, entäo, no primeiro tempo Deus se revelou como Pai, entre os pais que estiveram antes da lei; no segundo tempo o Filho é demonstrado no Anjo do Senhor, o qual é chamado de Deus e Senhor; o terceiro sucede a exibição do Espírito Santo que se expressa pelos reis e profetas; aparece no terceiro, ainda que sob um obscuro enigma, toda a Trindade, que é um Deus, ao mesmo tempo operante, e o qual năo é somente um Deus, mas Pai e Filho e Espírito Santo". 34

$\mathrm{O}$ quarto tempo, segundo Joaquim e conforme a quarta relação entre as pessoas (pela qual dois são enviados de um), é a época inaugurada pelo Filho e pelo Espírito Santo; o batismo de Jesus, que tem sobre ele a "pomba descida do céu", isto é, o Espirito Santo, significa que "ambos foram enviados pelo Pai para a redenção do genero humano"..$^{35}$ Finalmente, o quinto tempo é como descreve Joaquim:

\begin{abstract}
"Mas vejamos agora este quinto tempo, no começo do qual nós estamos, no qual o Espírito Santo enviado pelo Filho ainda deve agir e agirá muito mais poderosamente do que fez até aqui para que todos aprendam a honrar o Espirito Santo como honram o Pai e o Filho. Em que? Sem dúvida, no seu Evangelho. Pois não o honrará como convém quem não recebe com submissão e devoção o seu Evangelho. E qual é este Evangelho? Aquele do qual João diz no Apocalipse: 'Vi um anjo voando pelo meio do céu e lhe foi dado um evangelho eterno'. E o que é aquele Evangelho? O que procede do Evangelho de Cristo, pois a letra mata e o Espírito vivifica. É por isso que aquele que é a própria verdade, disse: 'Quando vier o Espirito de verdade, vos ensinará toda a verdade'. E para mostrar que este Evangelho tomará o Evangelho de Cristo e da Escritura, e como, mudando a água em vinho, inebriará os eleitos, acrescentou dizendo: 'Nāo falará por si próprio, mas falará tudo aquilo que ouvirá e a vós o anunciará. Ele me glorificará porque receberá do que é meu e o anunciará'. É necessáno, portanto, que ele mude as nossas mentes, o que ele pode fazer quando e como quer, como Deus, e que transfira os nossos corações dos desejos carnais para o amor das coisas celestes, para que, de algum modo, não sejamos mais o que fomos, mas comecemos a ser outros. $^{36}$
\end{abstract}

33

34

Sobre a diferença entre os cinco tempos, ver Psalterium $343 \mathrm{~s}$.

Psalt. p. 349: "Ouia igitur in primo tempore revelavit se Deus pater, sicut voluit et quibus patribus qui fuerunt ante legem, secundo adiuncta est demonstratio filii in angelo domini, qui et dominus vocatus est, tertio subsecuta est exhibitio spiritus sancti loquentis in regibus et prophetis, apparet quod in tertio tempore, licet sub obscuro aenigmate, totas trinitas, quae unus deus est, simul se ostenderit operari, et quod non una tantum persona esset deus, sed pater et filius et spiritus sanctus".

Ibid. p. 349: "... ad redimendum genus hominum ambos missos esse a patre".

Ibid. p. 351: "Sed iam nunc agendum est de tempore quinto in cuius initio sumus nos, in quo oportet adhuc spiritum sanctum missum a filio operari opera sua multo altius quam hactenus operatus est, ut omnes discant honorificare spiritum sanctum, sicut patrem et filium. In quo? haud dubiuem quod in evangelio eius. Non enim sicut honorificat illum, qui non subiectus et devotus recipit evangelium eius. Et quod est evangelium eius? illud de quo dicit Joannes in Apocalypsi: "Vidi angelum dei colantem per medium coelum, et datum est illi evangelium aetemum". Quod est evangelium eius? illud quod procedit de evangelio Christi: litera enim occidit, Spiritus autem vivificat: propter hoc enim veritas ipsa dicit: "Cum venerit ille spiritus veritatis docebit vos omnem veritatem"; et ut ostenderet quod de evangelio christi et de scriptura eius acciperet, et commutans quasi acquam in vinum inebriaret electos, adiecit et ait: "Non enim loquetur a semetipso sed quaecumque audiet loquetur et 
É de se notar que a história, através dos cinco tempos, é sempre a história na qual se manifesta o mistério da Trindade. Isto significa que Deus, ainda que de modos diversos e, por vezes, enigmáticos, presencia-se na história e faz desta o lugar mesmo para seu conhecimento. Neste sentido, a divisão da história em cinco tempos é mais apropriada pois ela indica a manifestação de cada Pessoa, não isoladas uma da outra, mas segundo as relações pessoais e é por essa razão que no último dos tempos torna-se manifesto, de forma clara, que Deus é três Pessoas e as três Pessoas são Deus. Eis aqui outra vez a relação íntima entre Deus e a história. Conhecer o primeiro representa para o homem estar na história à espera do Espírito que "ensinará toda a verdade". Decifrar na segunda o sentido mais oculto de sua existência é, na verdade, alcançar o conhecimento de Deus, meta que somente se atinge quando da Era do Espirito.

Deve-se considerar também que o Evangelho do Espírito, o evangelho eterno que 0 anjo do Apocalipse carrega, viria após a morte de Joaquim a ser considerado como um Terceiro Testamento. No entanto, não parece acertada tal consideração. O Evangelho do Espírito, como diz Joaquim, "procede do Evangelho de Cristo e da Escritura", isto é, dos dois testamentos, da mesma forma que a própria pessoa do Espírito procede de ambos (Pai e Filho) que se referem, respectivamente, ao Antigo e ao Novo Testamentos. Mas, então, qual é a boa nova, a notícia feliz que anunciará o Espírito? Que fará o Espírito para que "comecemos a ser outros"? Que transformação é esta que, como mudando a água em vinho, inebriará corações e mentes e os conduzirá ao conhecimento da verdade?

Certamente responder a tais questões é fundamental para que se compreenda o pensamento de Joaquim. Contudo, elas exigem um lugar apropriado para serem respondidas. Deixaremos para mais adiante esta tarefa e nos fixaremos agora na novidade que Joaquim apresenta no que diz respeito ao movimento histórico, que lhe fornece, como dissemos anteriormente, um princípio numa segunda acepção.

A Figura XI do Liber Figurarum é uma das que expressam com maior clareza o pensamento de Joaquim. Se na figura do Saltério (XIII) está representado o mistério trinitário, a figura dos Círculos Divinos ilustra a relação entre a Trindade e a história, expondo de que maneira os Estados relativos às pessoas divinas formam uma unidade, quer no próprio Deus, quer na história. São, de fato, três círculos que se justapōem, simbolizando, respectivamente, Pai, Filho e Espirito Santo e têm como fundo, perpassando todos os três círculos o nome ieue; ${ }^{37}$ à semelhança de cada pessoa, cada círculo indica o Primeiro, o Segundo e o Terceiro Estado. Duas observações devem ser feitas. A primeira é que por estarem justapostos cada círculo mantém uma seção de contato com os outros círculos. Assim, o círculo do Pai,

quae ventura sunt annuntiabit vobis. Ile me clarificabit quia de meo accipiet et annunciabit vobis". Oportet enim illum immutare mentes nostras, quod potest facere quando volt et prout vult, sicut deus, et transferre corda nostra a camalibus desideriis ad amorem coelestium, ut quodammodo non simus quod fuimus, sed alii esse incipiamus".

O nome ieue é a transcrição de iahweh. Originalmente, antes da reforma massoreta, este termo é apenas um tetragrama (YHVH) composto pelas letras iod, he, vav, que são como o espíito da língua, na medida em que sem elas é impossivel se pronunciar qualquer outra letra. Também tem como base o verbo haiá, que è o verbo ser no hebraico. Cf. N. Falbel "A critica de Aristóteles em Yehuda Halevi", in: Leopoldianum, vol XIII, n 38 9/86. 
do Velho Testamento e do Primeiro Estado, encontra-se com o círculo do Filho, do Novo Testamento e do Segundo Estado e ainda, com o círculo do Espirito Santo e do Terceiro Estado. Disto se segue que o centro da história encontra-se no ponto de interseção dos três círculos, quando as três Pessoas ao mesmo tempo são um Deus e, historicamente, são desta forma reconhecidas. A segunda observação é que os círculos, tomados agora como o próprio movimento histórico, representam passado, presente e futuro. E, neste sentido, porque cada círculo "invade" os outros, deve-se entender que, segundo Joaquim, o presente assume o seu passado em função do futuro. Cada acontecimento histórico é sempre o cumprimento de seu passado e a expectativa de seu futuro.

A partir da sugestiva figura dos círculos divinos podemos dar um passo decisivo na compreensão de Joaquim. Vimos que as divisões propostas por ele determinam limites para cada período histórico: que os três Estados têm início e fim (se bem que na Era do Espírito o fim não seja determinado); que nos cinco tempos já se encontra uma certa justaposição da manifestação histórica das pessoas, pautada nas relações pessoais; e, finalmente, que tais divisões não explicam, propriamente, a história em seu desenrolar. Ou seja, é preciso demonstrar que a história, possuidora de tais limites, não acontece como eventos isolados, de uma forma que se entenda que só o presente existe, mas ao contrário, a história como aparecimento e desaparecimento de cada momento presente "é" em virtude de seu passado, que se faz vigente possibilitando-o e do seu futuro ao qual é destinado. Estas considerações tornam-se claras entendendo a história a partir de um desenvolvimento vital, que leva em conta uma relação intrínseca entre os momentos da história, pelo qual passado, presente e futuro constituem o modo de ser da história. Vejamos como Joaquim apresenta esta relação:

"O primeiro Estado iniciou-se com Adão, frutificou em Abraão e terminou em Cristo. $O$ segundo Estado inicou em Zacarias, pai de João Batista, estimado para acabar nestes tempos. O terceiro Estado, tendo inicio com São Bento, começará a mostrar seu fruto a partir da vigésima segunda geração deste mesmo santo homem, deverá acabar no final dos tempos". ${ }^{38}$

Com esta passagem torna-se claro que os Estados da história não se sucedem simplesmente no tempo mas que estão relacionados de tal forma que o futuro esteja já no passado recolhidos ambos pelo presente. Vemos que o tempo que Joaquim vive (in temporibus istis) é o declínio, o fim (consumatio) da Era do Filho; seu inicio (initiatio, initium) deu-se com Ozias, quer dizer, durante a Era do Pai, e alcançou a sua maior expressão (fructificatio) através de Zacarias, pai de João Batista, o tipo do homem cristão. Agora, a frutificação da Era do Filho, que é o próprio João Batista e não Cristo, é também o declínio da Era do Pai, isto é, a figura histórica de João traz o modelo da prática cristã; nesta se encontra a superação do homem do primeiro Estado, de forma análoga a Cristo, que não é o iniciador do tempo cristão mas que ao frutificar determina o declínio da Segunda Era. Mas qual é o fruto que

38 Concordia 4, pt. 2,1 p. 405: "Primus status seculi initiatus est ab Adam, fructificavit ab Abraham, consumavit in Christo. Secundus initiatus ab Ozia, fructificavit a Zacharia patre Iohannis Baptiste, accepturus consumationem in temporibus istis. Tertius, sumens initium a beato Benedicto, cepit proferre fructum generatione vicesima secunda ab e odem sancto viro; consumandus et ipse en consumatione seculi." e também (2, pt. 1,4) p. 66, onde aparece initiatio e fructificatio. 
advém de Cristo e que, segundo Joaquim, estaria próximo de aparecer? 0 próprio Espirito. Historicamente se poderia pensar num único homem que encerrasse nele mesmo as características espirituais da verdade (como um predicador da verdade), mas a superação do tempo e da ordem cristãos é o próprio agir do Filho. Neste sentido é que Jesus, como escreve Joaquim, "é a própria verdade". Portanto, o homem espiritual, à semelhança do Espírito Santo, é a própria manifestação da verdade, da bem-aventurança que ensinou Jesus. E aqui, bem-aventurança não implica numa dimensão meta-histórica mas numa "praxis de vida". ${ }^{39}$

Devemos observar que o iniciador da Era do Pai é Adão e o da Era do Filho é Ozias. Estes inícios são, na verdade, uma confirmação, por parte de Joaquim, de que ambos os Estados devem terminar e deixar que verdade seja manifesta. Sem dúvida o pecado de Adão é mais grave que o do rei Ozias, mas ambos significam um começo faltoso. No caso de Ozias é, talvez, a condenação que Joaquim faz do seu próprio tempo, no qual assiste uma violação do poder espiritual por parte do poder temporal. Não podemos deixar de lembrar a postura renovadora que Joaquim almeja na Igreja, seja pela sua opção cisterciense, seja, principalmente, pela instauração da Ordo Florensis. ${ }^{40}$ Destarte a imperfeição dos Estados precedentes é necessário que estes declinem para o conhecimento pleno de Deus. Assim como a Era do Pai declinou e foi superada pela Era do Filho, agora, a Era do Filho deve declinar e ser superada pela Era do Espírito.

$O$ início do segundo Estado encontra-se no próprio Estado anterior: de igual modo, o início do terceiro Estado se dá na vigência do segundo Estado. Tal início é apontado em São Bento, fundador do monaquismo ocidental, do qual surgiriam os cistercienses e, portanto, o próprio Joaquim. Disto se conclui que o início, a frutificação e o declínio de cada Estado estão justapostos, bem como os círculos divinos. Sobre isto escreve Joaquim:

"[...] em todos estes tempos, os limites que são marcados não devem ser considerados absolutamente, mas deve ser considerado o inicio do seguinte a partir da metade do tempo presente e sua frutificação no fim do precedente" ${ }^{41}$

Isto evidencia que ao pensar a história Joaquim a considera a partir de seu modo de ser, isto é, a partir de sua historicidade. Initiatio, fructificatio e consumatio designam a realização da história. Initiatio é início, nascimento; fructificatio é também concepção, no sentido de trazer à luz, de clarificatio; consumatio é limite, fim, término, declínio. Ao compreender a história como nascimento, frutificação e declínio, Joaquim está aludindo ao ciclo vital, de nascimento e morte, que demarcam um certo instante do percurso histórico, como um intervalo temporal que frutifica e frutificando origina um outro intervalo, este, um outro e assim até o final dos tempos. Mas aqui devemos fazer uma observação. Dissemos que esta com-

39 Este sentido expressa Nietzsche quando escreve: "La bienaventuranza no es sólo una promesa: existe desde el momento en que se vive y se obra conforme a tales máximas e el Cristianismo es una praxis no una doctrina de fé." La Voluntad de Poderio. EDAF, Madrid, 1981.

40

A Ordem fundada por Joaquim foi aprovada por Celestino III, em 1196.

41 De Septem Sigilis p. 243: "[...] in omnibus temporibus istis non sunt iidem termini qui videntur notati in hac simpliciter attendendi, sed a medietate precedentis temporis initiatio sequentis attendenda est, clarificatio vero in limitibus suis" Cf. Mottu op. cit., 219. 
preensão da história está pautada num princípio de segunda acepção e que tal princípio é declínio e superação. Bem, a idéia do declínio provém de limes, de terminus, de consumatio. Contudo, o que não deixa de provocar uma certa inquietação é o fato de Joaquim utilizar o termo consumatio ${ }^{42}$ e não consummatio, o que seria correto gramaticalmente, pois consummatio provém do verbo consummare e não de consumere, cujo participio é consumptus. Alguns autores acreditam que o termo correto que Joaquim teria querido utilizar é consumatio. ${ }^{43}$ No entanto, é de se notar que se há um erro, ele se repete em várias passagens de sua obra. É de se pensar que o verbo utilizado é consummare (consumavit). No entanto, entre estes dois verbos há uma sutil diferença: consummare significa conduzir ao summus, isto é, à perfeição, ao mais elevado; enquanto consumere designa um enfraquecimento, uma destruição ou um declínio. Percebe-se quanto é inquietante esta distinção para se pensar a história segundo Joaquim.

A idéia de um declínio, como enfraquecimento, parece mais apropriada do que a de uma perfeição alcançada. Isto torna-se claro quando levamos em conta, primeiro, a Figura XX do Liber Figurarum ${ }^{44}$ na qual se lê defectus primus status, defectus secundi status, defectus tercii status; e segundo, tendo em vista que a perfeição designada pelo termo consummatio é colocada por Joaquim para um além da história, como éscreve no Psalterium Decem Chordarum:

"Aquilo que é dito no tempo médio, isto é, no tempo dos reis e profetas, é dito mais para expor os acontecimentos futuros in patria post finem mundi, do que para se crer que tantos mistérios terminariam naquele tempo. Portanto, no futuro século se alcançará a perfeição (consummandum est). ${ }^{45}$

Vemos que a idéia de uma perfeição é afastada pois, como diz Joaquim, in vita ista non est in veritate regnum sed exilium. ${ }^{46}$ Portanto, uma consumação em termos de perfeição é algo que Joaquim não impõe à história. Mas, se tal perfeição é negada, de que forma deve-se entender a "plenitude do sentido" que Joaquim anuncia se realizar com a Era do Espírito? Nisto, reside o significado que Joaquim concede aos homens espirituais e à sua ação, a salmódia.

Do que foi exposto entende-se que o declínio é o limite de todo existente. Não decerto como um fim que simplesmente acaba, como um passado que passou, mas como um passado que dispõe sempre, e a cada momento, determina a possibilidade de superação, uma supremacia do porvir. Declínio e superação se articulam, da mesma forma que o declínio da Era do Pai "coincide" com a frutificação da Era do Filho, da mesma forma que o declínio da Era do Filho "coincide" com a frutificação da Era do Espírito. Neste sentido, o passado se faz vigente no presente e este, porque declina, tem como destino a sua superação. $O$ exemplo histórico de Jesus é esclarecedor pois ele é o cumprimento de promessa (o passado) e o anún-

\footnotetext{
42 Ver nota 39.

43 Tanto Mottu quanto Crocco utilizam consummatio, embora no texto não apareça.

44 Ver ilustração.

45 Psalt. p. 351: "... illud quod de tempore medio dictum est, hoc est, de tempore Regum et Prophetarum, ad ostentionem magis factus est eorum quae futura sunt in patria post finem mundi, quam ut tunc causa tanti mysterii consumata fore credatur. Igitur in futuro saeculo consummandum est".

46. Ibid.
} 
cio do Paráclito (o porvir); ele é o "meio" da historia pois se manifesta entre os outros dois Estados, porque ele junto com o Pai enviam o Espírito, bem como no presente, passado e futuro se articulam.

Considerando que o declínio de uma Era coincide com a frutificação da Era seguinte, tem-se que o declínio não é somente um fim mas a superação que a própria Era presente possibilita. Frutificar é superar uma disposição presente; vale dizer, portanto, que declínio é um fim que é um começar de novo. E é neste sentido que a história é sempre recomeço, é uma repetição do ciclo de vida, uma renovação, um rejuvenescimento do homem, uma restauração da graça perdida: é o que significa a Era do Espírito, simbolizada pela criança. ${ }^{47}$

47 Conforme a divisão já apresentada (notal 17). 